\title{
In Vitro Multiplication of Ceropegia Bulbosa VAR. Lushii Roxb
}

\author{
Vinod Jogdand ${ }^{1}$, Laxman Shimple ${ }^{2}$, Narayan Pandhure ${ }^{3}$ \\ Department of Botany, Dr. Babasaheb Ambedkar Marathwada University, Aurangabad-431001
}

\begin{abstract}
CeropegiabulbosavarbulbosaRoxb is member of family Asclepiadaceae which was described by William Roxburgh. It is widely distributed, growing sporadically almost throughout India in red laterite soil. The leaves are subsessile to petiolate while Ceropegiabulbosa var. bulbosa has orbicular to ovate. It cures the disorder Urolithiasis which is the development of stones in the urinary tract. This may lead to pain and bleeding. It is considered as the third most common affliction of the urinary tract. In most of the types of stones that are formed, the most frequent are calcium oxalate. As per clinical and epidemiological studies, calcium oxalate followed by calcium phosphate is the most commonly encountered crystalline components found in urolithiasis. During present piece of work nodal explants from mature plant were surface sterilized and aseptically cultured on MS medium supplemented with various concentrations $(0.5,1.0$ and $3.0 \mathrm{mg} \mathrm{l-1)}$ of cytokinins (BAP and Kn) and auxins (IAA, NAA and 2, 4-D) alone and in various combinations under controlled condition. Successful regeneration was achieved by this method.
\end{abstract}

Keywords: CeropegiabulbosavarlushiiRoxb, Urolithiasis, Regeneration

\section{Introduction}

The genus Ceropegia was reported by 200 species distributed in the tropical and subtropical Asia, Africa, Australia and Malaysia and in the Canary and Pacific islands. In India 44 species of Ceropegia were found, out of them 27 species are endemic to the peninsular India which is distributed mainly in Western Ghats and most of them are enlisted under endangered category. Ceropegiaintermedia are also endemic and endangered species of South India. Scanty population of this species is distributed in edges of moist deciduous forests in Tamilnadu (Thomas and Philip, 2005). As the species is a cross pollinating one, the seed grown progenies of Ceropegia are not true-to-type. Low seed germination rate and habitat destruction threatens its population in natural habitat. The vegetative propagation by root tubers and stem cuttings is very arduous ().

The tuber of $C$. bulbosavarlushii contains valuable constituents which are used in many traditional Indian Ayurvedic drug preparations against many diseases. These include diarrhea and dysentery and these tubers are edible also.The tubers contain starch, sugar, gum, albuminoids, fats and crude fiber and are valuable constituents in many traditional medicinal systems in India. Active principle of tuberous roots contains an alkaloid ceropegine which is active against diarrhoea and dysentery (Nadkarni, 1976). Looking towards population it is necessary to conserve Ceropegia modern techniques like through tissue culture. During the present piece of work the apical shoot, Axillary bud and follicleswere taken as explants. Microropagation has been provides an effective alternative source for clonal propagation in Ceropegia.

\section{Material and Method}

\section{Preparation of Explants}

Explants viz. meristematic tissue, apical shoot, axillary bud and folicles(pods) of C.bulbosa were collected from elite plant growing in botanical garden, Department of Botany Dr. Babasaheb Ambedkar Marathwada University, Aurangabad.
The explants were washed carefully in running tap water for 10 minute followed by rinsing with distilled water for 5 minutes. For surface sterilization explants were treated with $70 \%$ ethanol for a minute followed by $\mathrm{Hgcl}_{2}(0.3 \%)$ for 5 minutes. This step was followed by three subsequent rinses with sterilized double distilled water aseptically. These explants were dissected into small pieces and inoculated so that maximum part can be exposed to nutrientmedia.

\section{Culture media}

MS medium (Murashige and Skoog, 1962) was used as a medium for multiplication.MS medium was fortified with combinations of growth hormones viz. BA, KIN for caulogenesis whereas auxins such as IAA, IBA, and NAA were usedfor rhizogenesis.MS medium enriched with $3 \%$ sucrose and gelled with $3 \mathrm{gm} / \mathrm{L}$ solidifying agent Clerigel, and the $\mathrm{pH}$ was adjusted to 5.8 after adding the growth regulators. The media was autoclaved under 15 psi and $121^{\circ}$ C.

\section{Culture conditions}

After aseptic inoculation cultures were transferred to culture room for incubation under a $16 \mathrm{~h}$ photoperiod supplied by white fluorescent tubes (2100-25000 lux) and maintained at $25 \pm 2^{0} \mathrm{C}$ temperatures. At least three replicates were maintainedfor each treatment.Observations were recordedafter 21 days. Mean $(\mu)$ values with the standard error (S.E.) values were calculated.

\section{Results and Discussion}

As explants of Ceropegia such as apical shoot, auxiliary buds and nodal explantswere grown on hormone free MS medium no effect was recordedon multiple shoots formation. When MS media was enriched with different concentrations of BAP viz. 1.0, 1.2, 1.4, 1.6, 1.8, $2.0 \mathrm{mg} / \mathrm{l}$ and combination of IBA, NAA highest rate of multiplication was recorded. 


\section{International Journal of Science and Research (IJSR) \\ ISSN (Online): 2319-7064 \\ Index Copernicus Value (2013): 6.14 | Impact Factor (2015): 6.391}

Table 1: Effect of BAP and IAA for multiplication of different explant

\begin{tabular}{|c|c|c|c|c|}
\hline \multirow{3}{*}{ Explant } & \multicolumn{2}{|c|}{$\begin{array}{c}\text { Conc. of growth } \\
\text { regulator (mg/L) }\end{array}$} & $\begin{array}{l}\text { Shoot length } \\
\text { (Mean } \pm \text { SE) }\end{array}$ & $\begin{array}{l}\text { \% of shoot } \\
\text { formation }\end{array}$ \\
\cline { 2 - 5 } & BAP & IAA & & \\
\hline apical shoot & 0.5 & 0.2 & $1.88 \pm 0.073$ & 30 \\
\cline { 2 - 5 } tip & 1.0 & 0.2 & $2.64 \pm 0.129$ & 32 \\
\cline { 2 - 5 } & 1.5 & 0.2 & $5.52 \pm 0.122$ & 37 \\
\cline { 2 - 5 } & 2.0 & 0.2 & $7.90 \pm 0.149$ & 51 \\
\cline { 2 - 5 } & 2.5 & 0.2 & $9.16 \pm 0.160$ & 49 \\
\cline { 2 - 5 } & 3.0 & 0.2 & $8.24 \pm 0.172$ & 47 \\
\hline Axillary bud & 0.5 & 0.2 & $6.70 \pm 0.130$ & 35 \\
\cline { 2 - 5 } & 1.0 & 0.2 & $8.04 \pm 0.143$ & 37 \\
\cline { 2 - 5 } & 1.5 & 0.2 & $8.14 \pm 0.140$ & 44 \\
\cline { 2 - 5 } & 2.0 & 0.2 & $9.62 \pm 0.139$ & 52 \\
\cline { 2 - 5 } & 2.5 & 0.2 & $8.76 \pm 0.214$ & 50 \\
\cline { 2 - 5 } & 3.0 & 0.2 & $7.82 \pm 0.149$ & 49 \\
\hline
\end{tabular}

*After 25 days mean \pm SE of 5 replicate

\section{Effect of BAP shoots multiplication}

The present investigation it was confined that explants viz. apical shoot, axillary bud and nodal explants was found effective for the development and multiple shoots formation. The two Cytokininsviz. BAP and KIN were tested. BAP was more effective than KIN for multiplication. MS media containing $3 \%$ sucrose, $3 \mathrm{mg} / \mathrm{L}$ Clerigel and different concentration of BAP 10.5, 1.0, 1.5, 2.0, 2.5, $3.0 \mathrm{mg} / \mathrm{l}$ alone and with IBA $0.2,0.4,0.6,0.8,1.0 \mathrm{mg} / \mathrm{L}$, were tested. Concentration of BAP along with NAA $0.2,0.4,0.6,0.8,1.0$ $\mathrm{mg} / \mathrm{L}$ gives average percentage of multiple shoots in Ceropegia.(Fig.1) Maximum number of multiple shoot wererecorded in case BAP $2.0 \mathrm{mg} / \mathrm{L}$, with combination IBA $0.2 \mathrm{mg} /$ L.(Fig.2, table 1)

Explant such as apical shoot and axillary bud were prominent to show results when inoculated on MS medium supplement with $3 \%$ sucrose, $2.5 \%$ Clerigel. Maximum shoot length and multiple shoot formation was recorded at 1.6 $\mathrm{mg} / \mathrm{L}$ BAP in combination with $0.2 \mathrm{mg} / \mathrm{L}$ IBA. Various concentrations of IAA were added into the MS medium to achieve rhizogenesis. Better in vitro rhizogenesis was achieved with $0.5 \mathrm{mg} / \mathrm{lit}$ IAA. Plants were hardened and planted in soil for field trails. In vitro regenerated plants had shown $75 \%$ viability.

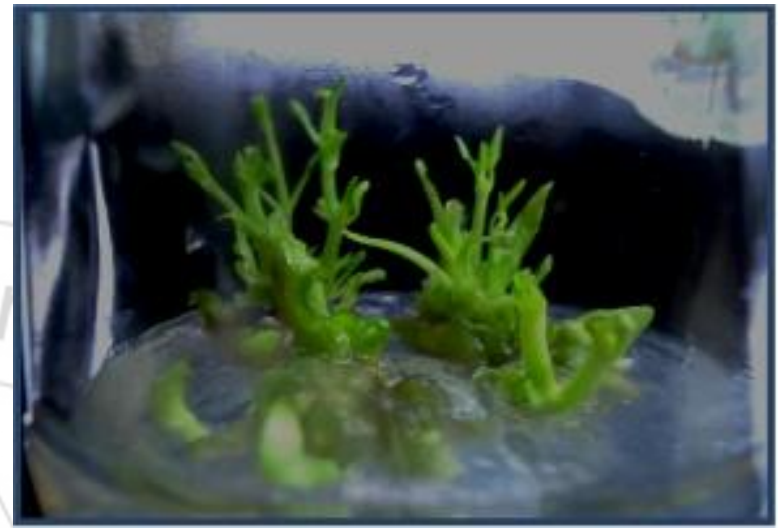

Figure 1: Multiple shoots formation along with callus
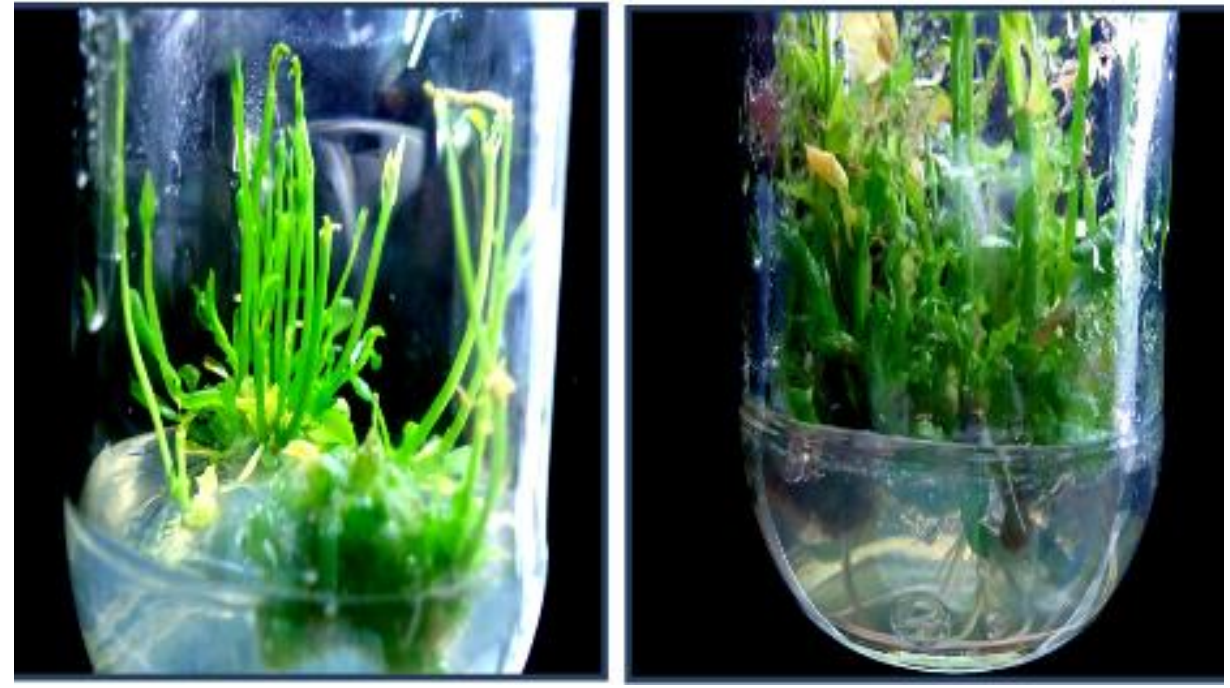

Figure 2: Multiple shoot formation along with tubers

Formation of tubers was recorded during growth of the cultures. The tubers are hard, light green in color and after subculture give rise to new plantlets. Similar results were recorded for callus and shoot multiplication using various explants in different plants like Tylophora indica (Gupta et al. 2010, Shah and Kapoor,1976). Proliferating shoot cultures was established by repeatedly sub culturing the mother explants on the hormone free medium. Repeated subculturing was said to be one of the methods of maintaining juvenility (Choudhary and Jha. 2004). In the present work highest number of shoot percentage was recorded in third sub culturing. Somatic embryos were developed into plantlets and subsequently grown to maturity (Kirtikar and Basu, 2001). These results indicate that nodal explants have high competence for somatic embryogenesis in Plumbago indica(Das and Rout, 2002). In the present study nodal explants have shown direct multiple shoot formation.

\section{Conclusion}

Conservation of plants in the changing scenario like draught and other calamities is a difficult task. Species of Ceropegia only appears in the nature after rainfall till end of September. 


\section{International Journal of Science and Research (IJSR) \\ ISSN (Online): 2319-7064}

Index Copernicus Value (2013): 6.14 | Impact Factor (2015): 6.391

Voracious collection of tubers of Ceropegias by the tribals is serious matter for the existence of these plants. Propagation is easier but further maintenance is difficult. Awareness for conservation of these species in nature is expected from local peoples. This protocol will really help for large scale propagation of these novel plants.

\section{Acknowledgement}

Authorsare thankful to the Head Department of Botany and University authorities for providing necessary facilities to carry out this piece of work.

\section{References}

[1] Choudhary KN, Ghosh B, jha S. (2004). May The root: a potential new source of competent cells for highfrequency regeneration in Tylophora indica, Plant cell report; 22(10):731-40

[2] Das G and Rout GR (2002) Plant regeneration through somatic embryogenesis in leaf derived callus of Plumbago indica. BiologiaPlantarum. 45(2): 299-302.

[3] Gupta Mayank, Singh Mhaveer, Mukhatr Hayat M., Ahmad Sayeed.( 2010). pharmacology journal (Vol2,Issue 11, Page 381-385

[4] Kirtikar KR, Basu BD (2001). Indian Medicinal Plants, Vol. $12^{\text {nd }}$ ed. Dehradun publisher Ltd, India, 1994; 1: 830-832.

[5] Murashige T. and Skoog F. (1962). A revised medium for rapid growth and bioassay for tobacco tissue cultures. Physiol. Plant. 15: 473-497.

[6] Nadkarni, K. M.( 1976). Indian materiamedica, vol. I. Bombay: Popular

[7] Prakashan;:303-304.

[8] Shah N.C., Kapoor L. D., (1976). Botany of Tylophora indica (Burm.f.) Merr, Vol. 14, No. 1, Pages 27-34

[9] Thomas D, Philip B (2005). Thidiazuron-induced highfrequency shoot organogenesis from leaf-derived callus of a medicinal climber, Tylophora indica. In Vitro Cellular and Dev. Biol. Plant, 41:124-128

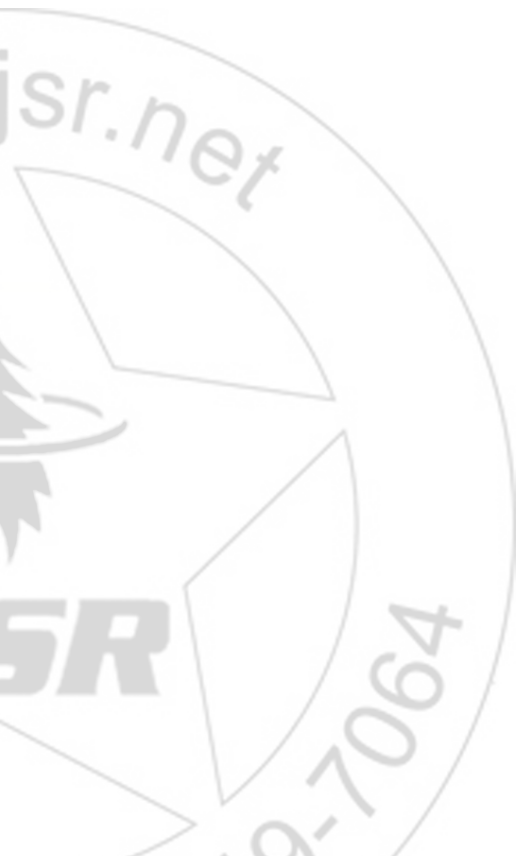

